\title{
The Gender Penalty: Reasons for Differences in Reported Weekly Work Hours Among Male and Female Family Physicians
}

\author{
Kathryn M. Hart, MD, FAAFP
}

(J Am Board Fam Med 2020;33:650-652.)

The $7 A B F M$ policy brief by Wilkensen et al ${ }^{1}$ highlights gender differences in work hours between male and female family physicians, with men reporting significantly more hours of total and direct patient care across age groups. This comes as no surprise to me as a female family physician with 3 young children who has shifted to part-time clinical work in no small part due to the competing demands of work and family. Many of my female medical school and residency classmates have followed similar paths. Some have left patient care altogether for administrative, research, or government positions, while others have transitioned to part-time clinical jobs. Traditional gender roles are still very much at play. The "invisible work" of raising children often falls on mothers, regardless of employment status. This begins with breastfeeding (and the natural carry-over to the intensive caregiving responsibilities of infancy) and evolves into scheduling doctor's appointments, completing school forms, coordinating activities, and arranging childcare, among thousands of other small tasks that cumulatively take up hours over the course of the week.

There has been a shift in recent years toward less-than-full-time work among physicians, ${ }^{2,3}$ with a smaller rate of decline in work hours for male physicians, older physicians, and those with fewer

From the Department of Family Medicine, Georgetown University School of Medicine.

Funding: None.

Conflict of interest: None.

Corresponding author: Kathryn M. Hart, MD, FAAFP, Georgetown University School of Medicine, MedStar Health at Spring Valley, 4910 Massachusetts Ave NW, 115, Washington DC 20016 (E-mail: kh1024@georgetown.edu).

See Related Article on Page 653. children. $^{2}$ Previous studies have also shown that family physicians are more likely to work part time compared with specialists. This likely reflects a cultural shift in medicine with millennial physicians placing a higher value on work-life balance over salary and career progression. ${ }^{4}$

Compared with previous generations, dual-career couples are more the norm, making childcare more logistically challenging. ${ }^{5}$ Younger male physicians are more than twice as likely as older male physicians to make career changes for their marriage and children. ${ }^{6}$ However, spouses of male physicians are less likely to work full-time than those of female physicians. ${ }^{7}$ Furthermore, female physicians in dual-physician relationships spend more time on domestic work than female physicians married to nonphysicians. ${ }^{8}$ The American Time Use Survey results from 2003 to 2016 showed that married female physicians spent significantly more time on household activities and childcare than male physicians, even after adjustment for respondent and spouse hours outside the home. ${ }^{9}$ Women physicians with children spent an additional 100.2 minutes per week than men, while female physicians without children spend 67.4 minutes. ${ }^{9}$ These pressures undoubtedly influence female physicians' tendency to work part time.

This work-hour gap not only has implications for the family physician workforce and patient access, but likely contributes to the "motherhood penalty," leading to known gender disparities in leadership positions and salary. ${ }^{10-12}$ While the survey sample described in the policy brief by Wilkensen at $\mathrm{al}^{1}$ did not capture early career physicians, gender disparities in new physicians and trainees are well documented in the literature. A survey of early career physicians revealed that women physicians were significantly more likely 
than their male counterparts to report not working full time. ${ }^{13}$ This gap increased in women with children and as time progressed after training. Women physicians currently working full time were more likely to report considering part-time work. Predictors for considering leaving clinical practice included lack of support from colleagues and superiors, lack of performance-related feedback from supervisors, and overtime. ${ }^{13}$ A majority of women working part time or not at all cite family as the reason for their decision. ${ }^{14}$

Pregnant residents are inclined to deny physical and psychological limitations and compensate by overworking. For example, many work right up to delivery, take extra call to compensate for time off during maternity leave, and truncate the duration of maternity leave. ${ }^{15,16}$ While fellow residents and program directors are generally supportive of colleagues who are pregnant, some colleagues may express feelings of resentment and hostility. ${ }^{15}$ Several studies have shown gender differences in perceptions of pregnant colleagues, with men being generally less supportive than women. ${ }^{17,18}$ In a survey of residents and fellows, female physicians were more likely to feel that having a child during training would burden colleagues and negatively impact their reputation and their future career success. ${ }^{19}$ Of respondents who had children, female physicians were more likely to be the primary caregivers on weeknights and weekends. This disparity is further exacerbated by a lack of institutional resources: only $38 \%$ of academic hospitals have childcare on site, and less than $60 \%$ have lactation rooms. ${ }^{20}$ Duration of breastfeeding is likely to be negatively affected by stigmatization of nursing mothers, lack of dedicated lactation rooms, and lack of time for pumping during busy clinical schedules. ${ }^{21}$ Despite all these challenges, reassuring data suggests that the disparity in wages and prestige of motherhood is time limited, with mothers' salaries and occupational achievement approaching those of childless women by middle age. ${ }^{10}$ In terms of wages, the majority of mothers report equivalent salaries to childless women by the time they reach their 40s. However, mothers of 3 or more children continue to experience wage penalties of $4 \%$ per child well into their 50 s, a phase of life when many are facing the burden of financing multiple college tuitions and saving for their own retirement.

Wilkensen et $\mathrm{al}^{1}$ noted that gaps in work hours were widest between the age ranges of 35 to 49 years and 60 to 69 years, surmising that caretaking may be responsible for the 60-to-69-year age-group gap. However, studies looking at the association between age and intention to leave clinical practice show conflicting evidence, with 1 study demonstrating the greatest intention to leave for those aged 33 to 35 years with declining intention to leave after the age of 50 years, ${ }^{22}$ while 3 others showed a higher intention to leave in older compared with younger physicians. ${ }^{23-25}$ One explanation for a lower intention to leave in younger physicians include a greater financial burden of raising young children. ${ }^{23}$ In addition, physicians nearing retirement may experience more burnout related to an evolving medical landscape that emphasizes quality metrics, electronic medical record documentation, condensed appointment times, and patient satisfaction scores.

Lack of acknowledgment of family responsibilities has been linked to lower job satisfaction and higher levels of stress and absenteeism. ${ }^{26}$ Clearly, systemic reforms are needed to support female family physicians in their multiple roles to improve work-life balance, especially now that women comprise more than half of the US medical school population. ${ }^{27}$ Reform will require the multi-level support of leaders in medicine, including clinical practitioners, administrators, academicians, and policy makers. This further underscores the need for younger female leaders in medicine who are likely to have different values about work-life balance than older male policy makers. ${ }^{6}$ Changes that have been proposed as "primary prevention" strategies to retain female physicians include the following: workplaces should offer affordable childcare with extended hours, dedicated lactation rooms, and parental leave coverage equivalent to that of the Family Medical Leave Act (12 weeks total, with 6 weeks' paid leave); competency-based advancement of resident trainees based on Accreditation Council for Graduate Medical Education (ACGME) milestones, with flexibility for length of training; and other measures to decrease work-related burden and increase job satisfaction, including more administrative support and time for continuing education. . $^{3,19,28,29}$

To see this article online, please go to: http://jabfm.org/content/ 33/5/650.full.

\section{References}

1. Wilkinson E, Coffman M, Petterson S, Jabbarpour Y. Gender differences in reported weekly work hours among family physicians. J Am Board Fam Med 2020;33:653-654.

2. Joyce CM, Wang WC, Cheng TC. Changes in doctors' working hours: a longitudinal analysis. Med Care Res Rev 2015;72:605-21. 
3. Staiger DO, Auerbach DI, Buerhaus PI. Trends in the work hours of physicians in the United States. JAMA 2010;303:747-53.

4. Lachish S, Svirko E, Goldacre MJ, Lambert T. Factors associated with less-than-full-time working in medical practice: results of surveys of five cohorts of UK doctors, 10 years after graduation. Hum Resour Health 2016;14:62-3.

5. EY. A global study on work-life challenges across generations: detailed findings. 2015. Available from: https://www.coursehero.com/file/52620735/EY-globalgenerations-a-global-study-on-work-life-challengesacross-generationspdf/.

6. Warde C, Allen W, Gelberg L. Physician role conflict and resulting career changes. gender and generational differences. J Gen Intern Med 1996;11:729-35.

7. Woodward CA, Williams AP, Ferrier B, Cohen M, Woodward CA. Time spent on professional activities and unwaged domestic work. is it different for male and female primary care physicians who have children at home? Can Fam Physician 1996; 42:1928-35.

8. Tesch BJ, Osborne J, Simpson DE, Murray SF, Spiro J. Women physicians in dual-physician relationships compared with those in other dual-career relationships. Acad Med 1992;67:542-4.

9. Ly DP, Jena AB. Sex differences in time spent on household activities and care of children among US physicians, 2003-2016. Mayo Clin Proc 2018;93:1484-7. https://www.ncbi.nlm.nih.gov/pubmed/29673711.

10. Kahn JR, García-Manglano J, Bianchi SM. The motherhood penalty at midlife: Long-term effects of children on women's careers. Fam Relat 2014;76: 56-72.

11. Rao AD, Nicholas SE, Kachniarz B, et al. Association of a simulated institutional gender equity initiative with gender-based disparities in medical school faculty salaries and promotions. JAMA Netw Open 2018;1:e186054.

12. Carr PL, Gunn CM, Kaplan SA, Raj A, Freund KM. Inadequate progress for women in academic medicine: findings from the national faculty study. J Womens Health (Larchmt) 2015;24:190-9.

13. Ochsmann EB. Thinking about giving up clinical practice? A gender-stratified approach to understanding junior doctors' choices. Academic Med 2012;87:91-7.

14. Frank E, Zhao Z, Sen S, Guille C. Gender disparities in work and parental status among early career physicians. JAMA Netw Open 2019;2:e198340.

15. Finch SJ. Pregnancy during residency: A literature review. Academic Med 2003;78:418-28.

16. Young-Shumate L. Pregnancy during graduate medical training. Academic Med 1993;68:792-9.
17. Tamburrino MB, Evans CL, Campbell NB, Franco KN, Jurs SG, Pentz JE. Physician pregnancy: Male and female colleagues' attitudes. J Am Med Womens Assoc 1992;47:82-4.

18. Franco K, Evans CL, Best AP, Zrull JP, Pizza GA. Conflicts associated with physicians' pregnancies. Am J Psychiatry 1983;140:902-4.

19. Kin C, Yang R, Desai P, Mueller C, Girod S. Female trainees believe that having children will negatively impact their careers: results of a quantitative survey of trainees at an academic medical center. BMC Med Educ 2018;18:260-1.

20. Sandler BJ, Tackett JJ, Longo WE, Yoo PS. Pregnancy and parenthood among surgery residents: results of the first nationwide survey of general surgery residency program directors. J Am Coll Surg 2016;222:1090-6.

21. Bresnahan M, Zhuang J, Anderson J, Zhu Y, Nelson J, Yan X. The "pumpgate" incident: stigma against lactating mothers in the U.S. workplace. Women Health 2018;58:451-65.

22. Bornschein S, Erbas B, Borelli S, et al. Arbeitszeit und arbeitszufriedenheit angestellter und beamteter arzte in München. Ergebnisse einer anonymen befragung. [Working hours and job satisfaction among physicians in hospitals and general practice in Munich. Results of an anonymous questionnaire] Gesundheitswesen 2006;68:535-44.

23. Sibbald B, Bojke C, Gravelle H. National survey of job satisfaction and retirement intentions among general practitioners in England. BMJ 2003;326:22.

24. Scott A, Gravelle H, Simoens S, Bojke C, Sibbald B. Job satisfaction and quitting intentions: a structural model of British general practitioners.Br J Industrial Relations 2006;44:519-540.

25. Estryn-Behar M, Fry C, Guetarni K, et al. Work week duration, work-family balance and difficulties encountered by female and male physicians: results from the French SESMAT study. Work (Reading, Mass.) 2011;40:83-100.

26. Thompson CA, Thomas CC, Maier M. Work-family conflict: Reassessing corporate policies and initiatives. In: Sekaran U LF, ed. Womanpower: managing in times of demographic turbulence. Newbury Park, CA: Sage Publications; 1992:61-78.

27. Barzansky B, Etzel SI. Medical schools in the United States, 2017-2018. JAMA 2018;320:1042-1050.

28. Section on medical students, residents, and fellowship trainees, committee on early childhood. Parental leave for residents and pediatric training programs. Pediatrics 2013;131:387-390.

29. Bovier PA, Perneger TV. Predictors of work satisfaction among physicians. Eur J Public Health 2003;13:299-305. 